\title{
Vital Signs Are Not Associated with Self-Reported Acute Pain Intensity in the Emergency Department
}

\author{
Raoul Daoust, MD, $\mathrm{MSc}^{*^{\dagger}}$; Jean Paquet, $\mathrm{PhD}^{* \ddagger}$; Benoit Bailey, MD, MSc ${ }^{\dagger \S}$; Gilles Lavigne, DMD, \\ $\mathrm{PhD}^{\ddagger \pi}$; Éric Piette, $\mathrm{MD}, \mathrm{MSc}^{*}$; Karine Sanogo, $\mathrm{MD}^{\|}$; Jean-Marc Chauny, MD, $\mathrm{MSc}^{*}$
}

\section{ABSTRACT}

Objectives: This study aimed to ascertain the association between self-reported pain intensity and vital signs in both emergency department (ED) patients and a subgroup of patients with diagnosed conditions known to produce significant pain.

Methods: We performed a retrospective analysis of real-time, archived data from an electronic medical record system at an urban teaching hospital and regional community hospital. We included consecutive ED patients $\geq 16$ years old who had a self-reported pain intensity $\geq 1$ as measured during triage, from March 2005 to December 2012. The primary outcome was vital signs for self-reported pain intensity levels (mild, moderate, severe) on an 11-point verbal numerical scale. Changes in pain intensity levels were also compared to variations in vital signs. Both analyses were repeated on a subgroup of patients with diagnosed conditions recognized to produce significant pain: fracture, dislocation, or renal colic. Results: We included 153,567 patients (mean age of $48.4 \pm 19.3$ years; $55.5 \%$ women) triaged with pain (median intensity of $7 / 10 \pm 3$ ). Of these, $8.9 \%$ of patients had diagnosed conditions recognized to produce significant pain. From the total sample, the difference between mild and severe pain categories was 2.7 beats/minutes (95\% Cl: $2.4-3.0$ ) for heart rate and $0.13 \mathrm{~mm} \mathrm{Hg}(95 \% \mathrm{Cl}:-0.26-0.52)$ for systolic blood pressure. These differences generated small effect sizes and were not clinically significant. Results were similar for patients who experienced changes in pain categories and for those conditions recognized to produce significant pain.

Conclusion: Health care professionals cannot use vital signs to estimate or substantiate self-reported pain intensity levels or changes over time.

\section{RÉSUMÉ}

Objectif: L'étude visait à confirmer l'existence d'une association entre l'intensité de la douleur autodéclarée et les signes vitaux enregistrés chez des patients au service des urgences
(SU) ainsi que dans un sous-groupe de malades souffrant d'affections connues pour causer de fortes douleurs.

Méthode: Les auteurs ont procédé à une analyse rétrospective de données enregistrées en temps réel et archivées dans un système de dossiers médicaux électroniques, dans un centre hospitalier universitaire urbain et dans un hôpital communautaire régional. Ont participé à l'étude des patients consécutifs, âgés de $\geq 16$ ans, qui ont fait état, au SU, de douleurs d'une intensité $\geq 1$, mesurée durant le triage, de mars 2005 à décembre 2012. Le principal critère d'évaluation était les signes vitaux associés à différents degrés d'intensité (légère, modérée, forte) de la douleur autodéclarée sur une échelle numérique, verbale, de 11 points. Les variations de l'intensité de la douleur ont également été comparées aux variations des signes vitaux. Les deux analyses ont été reprises dans un sous-groupe de patients souffrant d'affections connues pour causer de fortes douleurs: fracture, luxation ou colique néphrétique.

Résultats: Ont participé à l'étude 153567 patients (âge moyen: $48,4 \pm 19,3$ ans; femmes: $55,5 \%$ ) éprouvant des douleurs durant le triage (intensité médiane: $7 / 10 \pm 3$ ). De ce nombre, 8,9\% souffraient d'affections connues pour causer de fortes douleurs. L'écart entre les douleurs légères et les douleurs intenses était de 2,7 battements/minute (IC à 95\%: 2,4-3,0) pour la fréquence cardiaque et de $0,13 \mathrm{~mm} \mathrm{Hg}$ (IC à $95 \%$ : $-0,26-0,52$ ) pour la pression systolique, dans l'ensemble de l'échantillon. L'ampleur de l'effet était faible et l'écart, sans importance sur le plan clinique. Des résultats similaires ont été enregistrés chez les patients éprouvant des douleurs d'intensité suffisamment variable pour changer de catégorie et chez ceux souffrant d'affections connues pour causer de fortes douleurs.

Conclusions: Les professionnels de la santé ne peuvent pas s'appuyer sur les signes vitaux pour estimer ou confirmer l'intensité de la douleur autodéclarée et les variations d'intensité au fil du temps.

Keywords: Pain intensity, vital signs, emergency department

From the *Department of Emergency Medicine, Research Centre, Hôpital du Sacré-Coeur de Montréal, Montréal, Québec, Canada; †Faculty of Medicine, Université de Montréal, Montréal, Québec, Canada; $¥$ Center for Advanced Research in Sleep Medicine, Hôpital du Sacré-Coeur de Montréal, Montréal, Québec, Canada; §Division of Emergency Medicine, Department of Pediatrics, Centre hospitalier universitaire Sainte-Justine, Montréal, Québec, Canada; đFaculties of Dental Medicine and Medicine, Université de Montréal, Montréal, Quebec, Canada; and \|Department of Emergency Medicine, Hôpital régional de St-Jérôme, St-Jérôme, Québec, Canada.

Correspondence to: Dr. Raoul Daoust, Department of Emergency Medicine, Hôpital du Sacré-Coeur de Montréal, 5400 boul. Gouin ouest, Montreal, Quebec, Canada, H4J 1C5; E-mail: raoul.daoust@umontreal.ca 


\section{INTRODUCTION}

Pain is the most common chief complaint leading to emergency department (ED) visits. ${ }^{1-3}$ Optimal pain management is lacking in most EDs, as many patients do not receive analgesia ${ }^{3-12}$ and time to analgesic administration is often too long. ${ }^{3,5-8,10-19}$ Most health care professionals underestimate pain intensity. ${ }^{20,21} \mathrm{In}$ the absence of tachycardia or hypertension, we observed that ED staff tend to discredit self-assessments of severe pain when patients do not appear to be suffering. Health care professionals have also noted variations in heart rate (HR) and blood pressure associated with changes in pain intensity, validating their notion that pain intensity levels are linked with significant fluctuations in vital signs. However, in the prehospital and ED literature, it is unclear how useful vital signs are for predicting pain intensity. ${ }^{22-30}$

Pain intensity is subjective, and with conflicting results, researchers have tried to identify unbiased parameters (including vital signs) to validate pain intensity. HR (or HR variability), more than blood pressure, has been associated with pain intensity, ${ }^{22-24,27,31-34}$ but mostly in males. ${ }^{29,30}$ Some studies do not support this association. ${ }^{35-38}$ Systolic (SBP), diastolic (DBP), and mean arterial pressure (MAP) have been associated with pain intensity. ${ }^{24,26}$ However, as was the case for HR, other investigations reported an absence of relationship. ${ }^{28,33,35,39}$ Most studies have failed to show an association between pain and respiratory rate. $22,24,26,28,31,33,37,39$ Transcutaneous oxygen, skin conductance, and the analgesia/nociception index (calculated from HR variability) have been assessed in patients experiencing pain with inconsistent conclusions. $^{23,27,31,32,34,38,40-42}$

Patients with severe pain who show no hypertension or tachycardia to substantiate their pain intensity might not receive the aggressive pain treatment they warrant. Our study aimed to determine whether vital signs are associated with pain intensity levels in both the ED population and a subgroup of patients with diagnosed conditions recognized to produce significant pain. In the same populations, we also investigated whether changes in vital signs in individual patients are coupled with variations in pain intensity levels over time. We hypothesized that ED patients, especially those with recognized painful conditions, will demonstrate a weak association between vital signs and self-reported pain intensity levels.

\section{METHODS}

\section{Study design and setting}

We undertook retrospective analysis of real-time, archived data from electronic medical prescription and nursing record systems in the ED of two health care institutions:, a tertiary academic urban hospital with an annual census of approximately 60,000 ED visits per year, and a secondary regional community hospital with approximately 48,000 ED visits per year. The computerized system included demographic data, final diagnosis, triage information (reason for ED visit pain assessment, vital signs), and subsequent vital signs and pain intensity evaluation during ED stay. All information was collected in real time and time-stamped. The study was approved by the ethics review boards of both institutions.

\section{Selection of participants and study protocol}

All consecutive patients over 16 years of age with pain intensity at triage of 1 or more on an 11-point verbal numerical scale (VNS) who presented to the tertiary urban hospital between March 2008 and December 2012 , or to the secondary regional hospital between March 2005 to December 2012, were included in the study. To evaluate pain intensity, nurses instructed patients to rate their pain between 0 , representing "no pain," and 10, representing "the worst pain imaginable." Vital signs were measured by automated electronic sphygmomanometer. From the database, we extracted: gender, age, Canadian Triage and Acuity Scale (CTAS) priority level (high $=1,2$; low $=3,4,5$ ), arrival mode (ambulance or walk-in), ED visit duration, disposition after ED (admission or release) and final diagnosis charted by ED physicians. Pain intensity, HR, SBP, and DBP recorded at triage and at first evaluation during the ED stay were selected for analyses. MAP was calculated as $[(2 \times$ diastolic $)+$ systolic $] / 3$. As our primary outcome, we studied the associations between pain intensity categorized as mild (VNS 1-3), moderate (VNS 4-6), or severe (VNS 7-10) ${ }^{43}$ and values of HR, $\mathrm{SBP}, \mathrm{DBP}$, and MAP.

For our secondary outcomes, we selected a subgroup of patients with two assessments of pain intensity within the first 24 hours of their ED stay and ascertained whether changes in pain intensity levels in this population were linked with variations in HR, SBP, DBP, 
or MAP. We also studied the same associations in patients with diagnosed conditions recognized to produce significant pain: fracture, dislocation, and renal colic. These diagnoses were identified in a focus group of ED physicians from the tertiary urban hospital. The group was instructed to find ED diagnoses that physicians would unanimously agree on as having a pain intensity generated by "genuine" painful stimuli. All analyses were repeated, excluding patients with a pacemaker or taking beta-blocker medication known to possibly affect vital signs.

\section{Statistical analyses}

Patients' characteristics from the two hospitals were compared by $\chi^{2}$, Mann-Whitney, and independent $t$-tests, depending on the scale of the variables. Because of the large sample size, Cohen's effect sizes (ES) were reported instead of significance levels. To compare vital signs at triage for the three pain intensity categories, a one-way analysis of variance (ANOVA) was performed for each vital sign.

A one-way ANOVA was also conducted for the subgroup of patients with two pain intensity assessments, to compare differences in vital signs associated with pain intensity category differences. Pain intensity differences were divided into four categories: 1) "major drop," i.e., patients with severe pain intensity at triage and mild pain intensity at second evaluation; 2) "minor drop," i.e., severe to moderate or moderate to mild pain intensity; 3) "stable," i.e., no change in pain intensity between the two evaluations; and 4) "increased," i.e., heightened pain intensity level at the second evaluation. We did not distinguish between minor and major increases because, in the context of pain management in EDs, very few patients presented with a major increase in pain intensity level. For all one-way ANOVAs, Cohen's (f) ES were reported. They are described as: small $=0.10$, moderate $=0.25$, and large $=0.40$. An ordinal logistic regression was first performed to evaluate the contribution of vital signs to pain intensity level during triage, controlling for age and gender. However, the assumption that "the relationship between each pair of outcomes was the same" was rejected in all our analyses. Multinomial logistic regressions served as an alternative, to facilitate interpretation; only odds ratios (OR) $\pm 95 \%$ confidence intervals (CI) of mild as opposed to severe pain intensity category were reported. To facilitate clinical interpretation, dichotomous variables were created from vital signs with the threshold suggested by Bendall et $\mathrm{al}^{4}: \mathrm{HR} \geq 100$ beats $/ \mathrm{min}, \mathrm{SBP} \geq 140 \mathrm{~mm} \mathrm{Hg}$, and $\mathrm{DBP} \geq 90 \mathrm{~mm} \mathrm{Hg}$. All analyses were made with SPSS version 20 (IBM, Somers, NY).

\section{RESULTS}

During our study period, 153,567 patients aged 16 years or older were triaged with a pain intensity of at least $1 / 10$, and 13,691 patients $(8.9 \%)$ had a diagnosed condition recognized to produce significant pain (Figure 1). Patient characteristics were clinically similar for the two health care institutions, except for longer median length of stay and higher percentage of arrival by ambulance at the secondary regional hospital (Table 1). The results for all outcomes were not different between hospitals, so they were pooled. Eight percent of the patients had a pacemaker or had taken beta-blocker medication prior to or during the study. Results including or excluding those patients were similar; therefore, results for the whole sample are presented.

The mean age of our entire cohort was 48.4 years $(\mathrm{SD} \pm 19.3), 55.5 \%$ were women, and $22.3 \%$ were 65 years old or older. Median pain intensity was $7 / 10$ $(\mathrm{IQR} \pm 3)$. Because our sample size was large, statistically significant differences $(p<0.001)$ in HR, SBP, DBP, and MAP were evident between each category of pain intensity: the difference between mild and severe pain intensity categories for HR was 2.7 beats/min (95\% CI: $2.4-3.0$ ), $0.13 \mathrm{~mm} \mathrm{Hg}$ (95\% CI: $-0.26-0.52$ ) for SBP, $1.5 \mathrm{~mm} \mathrm{Hg}$ (95\% CI: $1.2-1.7)$ for DBP, and $1.0 \mathrm{~mm} \mathrm{Hg}$ (95\% CI: $0.76-1.3)$ for MAP. However, these differences were not clinically significant and generated very small ES $(<0.10)$ (Figure 2). The results were similar for diagnosed conditions recognized to produce significant pain (fracture, dislocation, and renal colic): the difference was 1.3 beat/ min (95\% CI: $0-2.7)$ for $\mathrm{HR}, 3.6 \mathrm{~mm} \mathrm{Hg}(95 \% \mathrm{CI}$ : $1.6-5.5)$ for SBP, $3.5 \mathrm{~mm} \mathrm{Hg}$ (95\% CI: $2.2-4.8$ ) for DBP, and $3.5 \mathrm{~mm} \mathrm{Hg}$ (95\% CI: 2.2 - 4.9) for MAP.

Table 2 presents the results of multinomial logistic regressions, predicting pain severity as a function of each vital sign, adjusted for age and gender for both the entire sample and in patients with conditions recognized to produce significant pain. For the entire sample, vital signs demonstrated low odds ratio $(\mathrm{OR})(\leq 1.3)$, with age and gender producing generally higher OR than vital signs. The results were similar for patients with conditions recognized to produce significant pain;however, age and HR were no longer significant predictors. 
Tertiary urban hospital

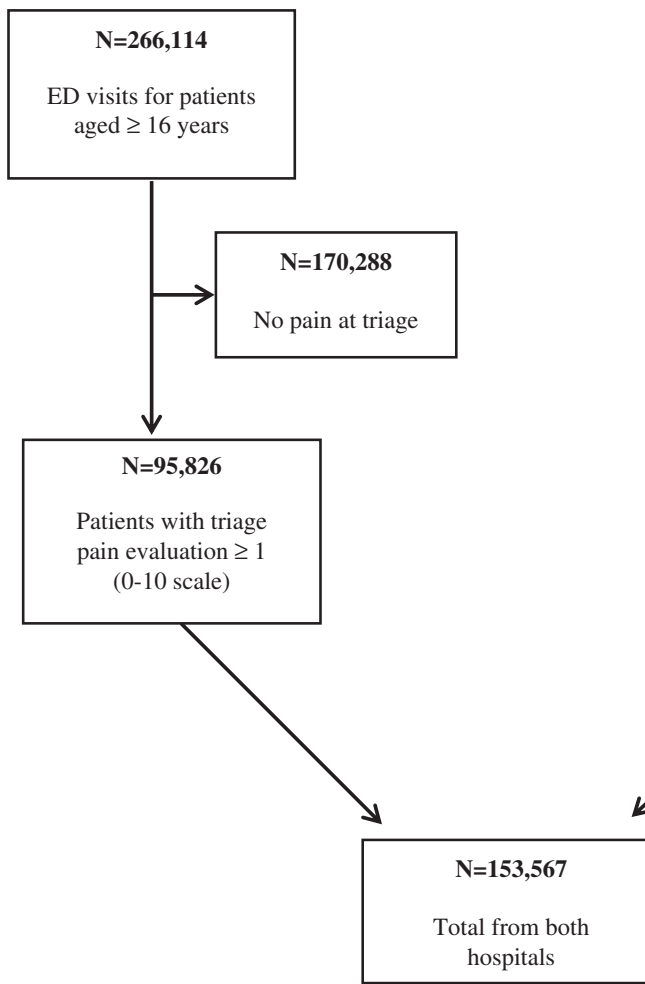

\section{Secondary regional hospital}

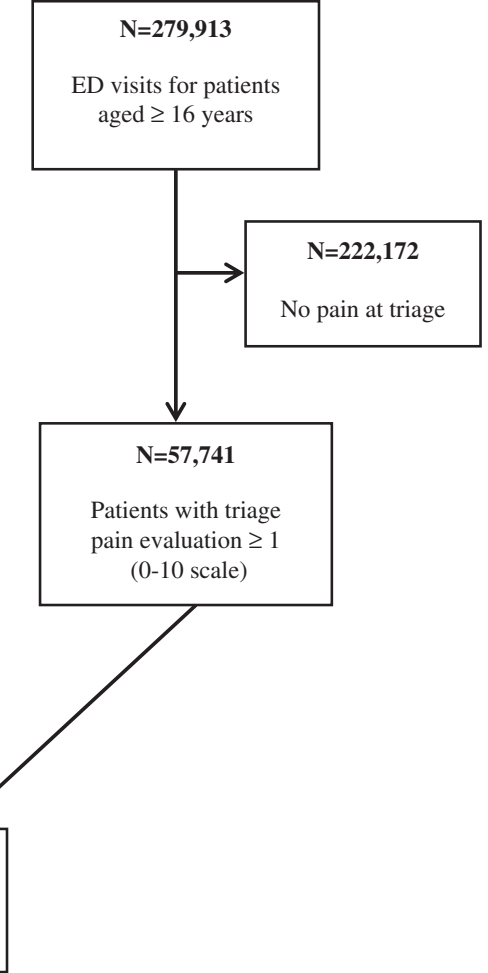

Figure 1. Flow chart of patients' selection.

\begin{tabular}{|c|c|c|c|}
\hline Patient variables & $\operatorname{HSCM}^{*}(\mathrm{~N}=95,826)$ & $\mathrm{HRSJ}^{+}(\mathrm{N}=57,741)$ & Effect size \\
\hline \multicolumn{4}{|l|}{ Sex (\%): } \\
\hline Female & 56.9 & 53.2 & 0.04 \\
\hline Male & 43.1 & 46.8 & \\
\hline Mean age $( \pm S D)$ : & $48.3(19.3)$ & $48.6(19.1)$ & 0.01 \\
\hline \multicolumn{4}{|l|}{ Age $(\%)$} \\
\hline$<65$ years & 77.7 & 77.8 & $<0.01$ \\
\hline$\geq 65$ years & 22.3 & 22.2 & \\
\hline \multicolumn{4}{|l|}{ Type of arrival (\%): } \\
\hline Ambulance & 16.4 & 26.4 & 0.12 \\
\hline Standing & 83.6 & 73.6 & \\
\hline \multicolumn{4}{|l|}{ Urgency level (\%): } \\
\hline High & 20.2 & 18.5 & 0.02 \\
\hline Low & 79.8 & 81.5 & \\
\hline \multicolumn{4}{|c|}{ Diagnosed conditions ${ }^{\ddagger}$ recognized to produce significant pain (\%): } \\
\hline Yes & 8.1 & 10.2 & 0.04 \\
\hline No & 91.9 & 89.8 & \\
\hline Visit duration (h): median (Q25-O75) & $6.8(4.4-10.9)$ & $10.2(5.4-19.7)$ & 0.20 \\
\hline Median pain intensity level at triage $( \pm \mid \mathrm{I} R)$ : & 7 (3) & 7 (3) & 0.02 \\
\hline Mean heart rate $( \pm S D)$ : & $82.0(15.3)$ & 83.9 (16.9) & 0.12 \\
\hline Mean systolic blood pressure $( \pm S D)$ : & $133.2(20.5)$ & $136.8(23.6)$ & 0.16 \\
\hline Mean diastolic blood pressure $( \pm S D)$ : & $80.4(14.6)$ & $77.0(13.0)$ & 0.25 \\
\hline Mean arterial pressure $( \pm S D)$ : & $98.0(15.2)$ & $96.9(14.8)$ & 0.07 \\
\hline
\end{tabular}



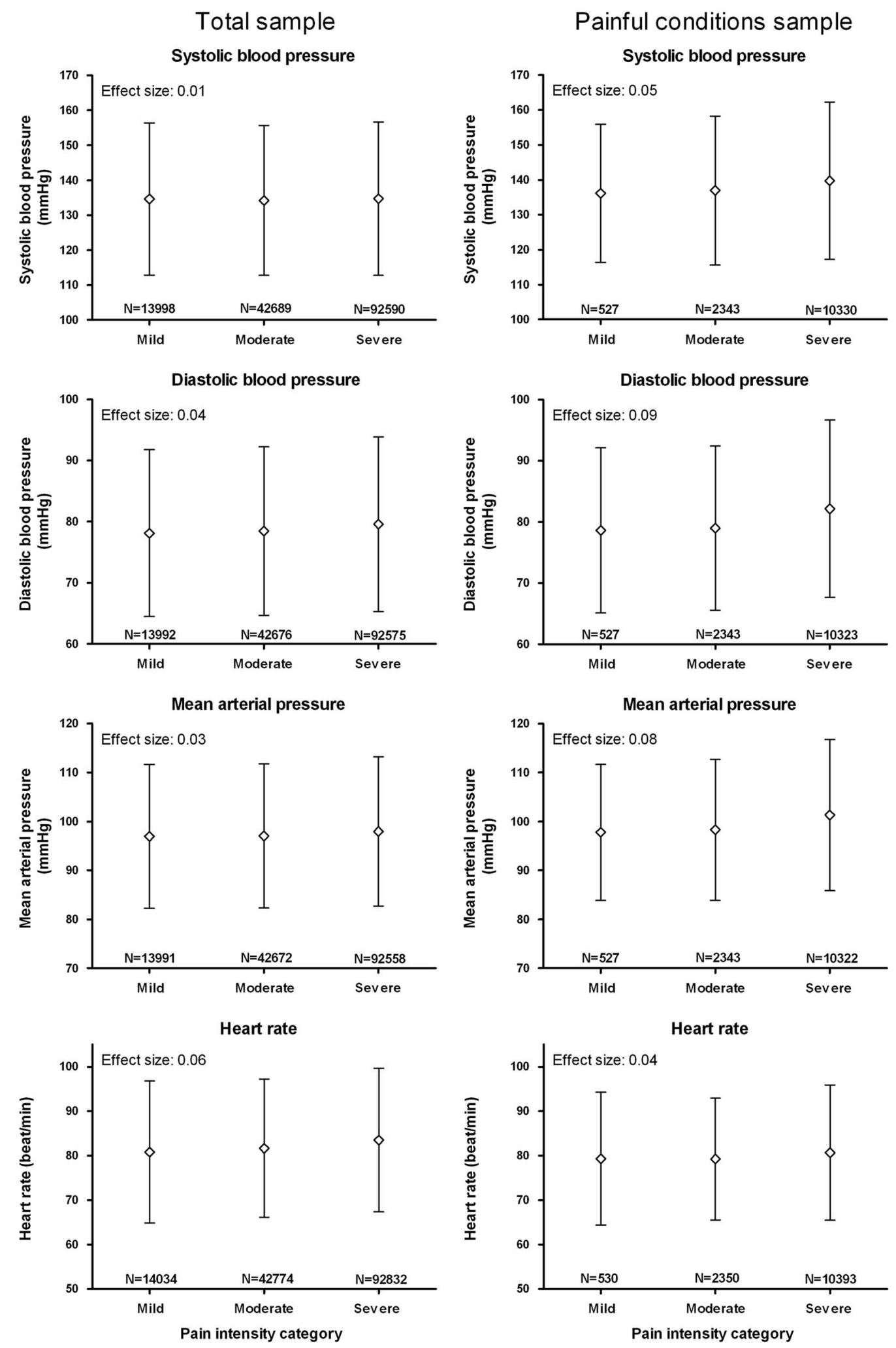

Figure 2. Mean $( \pm S D)$ systolic, diastolic, mean arterial blood pressure and heart rate as a function of three levels of triage pain intensity in the overall sample and in patients with recognized painful conditions. Cohen's one-way ANOVA effect sizes are also reported. 


\begin{tabular}{|c|c|c|}
\hline Variables & Odd Ratios & $95 \% \mathrm{Cl}$ \\
\hline \multicolumn{3}{|l|}{ Entire sample: ( $N=153,567)$} \\
\hline Heart rate: $\geq 100$ beats/min & 1.33 & $1.26-1.40$ \\
\hline Age: $<65$ & 1.29 & $1.24-1.35$ \\
\hline Gender: female & 1.53 & $1.47-1.58$ \\
\hline Systolic blood pressure: $\geq 140 \mathrm{~mm} \mathrm{Hg}$ & $1.09^{*}$ & $1.05-1.13$ \\
\hline Age: $<65$ & 1.34 & $1.28-1.40$ \\
\hline Gender: female & 1.56 & $1.50-1.62$ \\
\hline Diastolic blood pressure: $\geq 90 \mathrm{~mm} \mathrm{Hg}$ & 1.31 & $1.25-1.36$ \\
\hline Age: $<65$ & 1.32 & $1.27-1.38$ \\
\hline Gender: female & 1.58 & $1.52-1.64$ \\
\hline \multicolumn{3}{|c|}{ Diagnosed conditions $^{\dagger}$ recognized to produce significant pain sample: $(N=13,691)$} \\
\hline Heart rate: $\geq 100$ beats/min & 1.14 & $0.85-1.53$ \\
\hline Age: $<65$ & 1.00 & $0.80-1.25$ \\
\hline Gender: female & 1.51 & $1.25-1.83$ \\
\hline Systolic blood pressure: $\geq 140 \mathrm{~mm} \mathrm{Hg}$ & 1.35 & $1.13-1.62$ \\
\hline Age: $<65$ & 1.08 & $0.86-1.35$ \\
\hline Gender: female & 1.59 & $1.32-1.93$ \\
\hline Diastolic blood pressure: $\geq 90 \mathrm{~mm} \mathrm{Hg}$ & 1.71 & $1.38-2.12$ \\
\hline Age: $<65$ & 1.01 & $0.81-1.26$ \\
\hline Gender: female & 1.62 & $1.34-1.96$ \\
\hline
\end{tabular}

The median time between two consecutive pain intensity assessments (at triage and second evaluation within 24 hours) used to examine associated vital signs changes over time was 2.9 hours $(\mathrm{IQR}=5.4)$. Also, because our sample size was large, changes in pain intensity were significantly associated withvariations in HR, SBP, DBP, and MAP (Figure 3). Differences between the "major drop" and "increased" categories of change in pain intensity were 3.4 beats/min $(95 \% \mathrm{CI}$ : 2.4 - 4.4) for $\mathrm{HR}, 8.8 \mathrm{~mm} \mathrm{Hg}$ (95\% CI: 7.2 - 10.4) for SBP, $6.2 \mathrm{~mm} \mathrm{Hg}(95 \% \mathrm{CI}: 5.0-7.4)$ for DBP, and $7.1 \mathrm{~mm} \mathrm{Hg}$ (95\% CI: 5.9-8.3) for MAP. For conditions recognized to produce significant pain, changes were generally larger (except for HR) with: 2.1 beats/ $\min (95 \% \mathrm{CI}:-0.48-4.7)$ for $\mathrm{HR}, 17.5 \mathrm{~mm} \mathrm{Hg}(95 \%$ CI: $13.0-21.9)$ for SBP, $11.2 \mathrm{~mm} \mathrm{Hg}$ (95\% CI: $8.1-14.3)$ for $\mathrm{DBP}$, and $13.5 \mathrm{~mm} \mathrm{Hg}$ (95\% CI: $10.3-16.6)$ for MAP. However, they only represented small to moderate ES.

\section{DISCUSSION}

To the best of our knowledge, this is the largest cohort study exploring the association between vital signs and acute pain intensity. We found small ES (0.01 to 0.04 ) for blood pressure and for pulse (0.06), confirming that vital signs should not substantiate self-reported acute pain intensity level in the ED. Our results are similar to those of other studies in ED, prehospital, or military settings. ${ }^{25,28,36,37,39}$ For example, Bendall et al demonstrated, in a retrospective prehospital study, a slightly increased likelihood of severe pain if: $\mathrm{HR}$ is $\geq 100$ beats $/ \mathrm{min}$ for patients $\leq 64$ years old, or if SBP was $\geq 140 \mathrm{~mm} \mathrm{Hg}$ for patients $\geq 65$ years old ( $18 \%$ and $14 \%$, respectively). However, these authors concluded: "Simple correlation fails to show clinically important association between prehospital vital signs and pain severity." 24 Ledowski et al established that plasma epinephrine and norepinephrine levels in a postoperative population were generally not associated with pain intensity, the only exception being norepinephrine level changes for major changes in pain intensity. They concluded that "the absence of signs of sympathetic stimulation cannot be seen as a guarantee for absence of significant pain." 39

As stated in our introduction, some literature supports a relationship between vital signs and pain intensity, but most studies had a small sample or were derived from post-operative and/or laboratory settings. 
Total sample

Systolic blood pressure
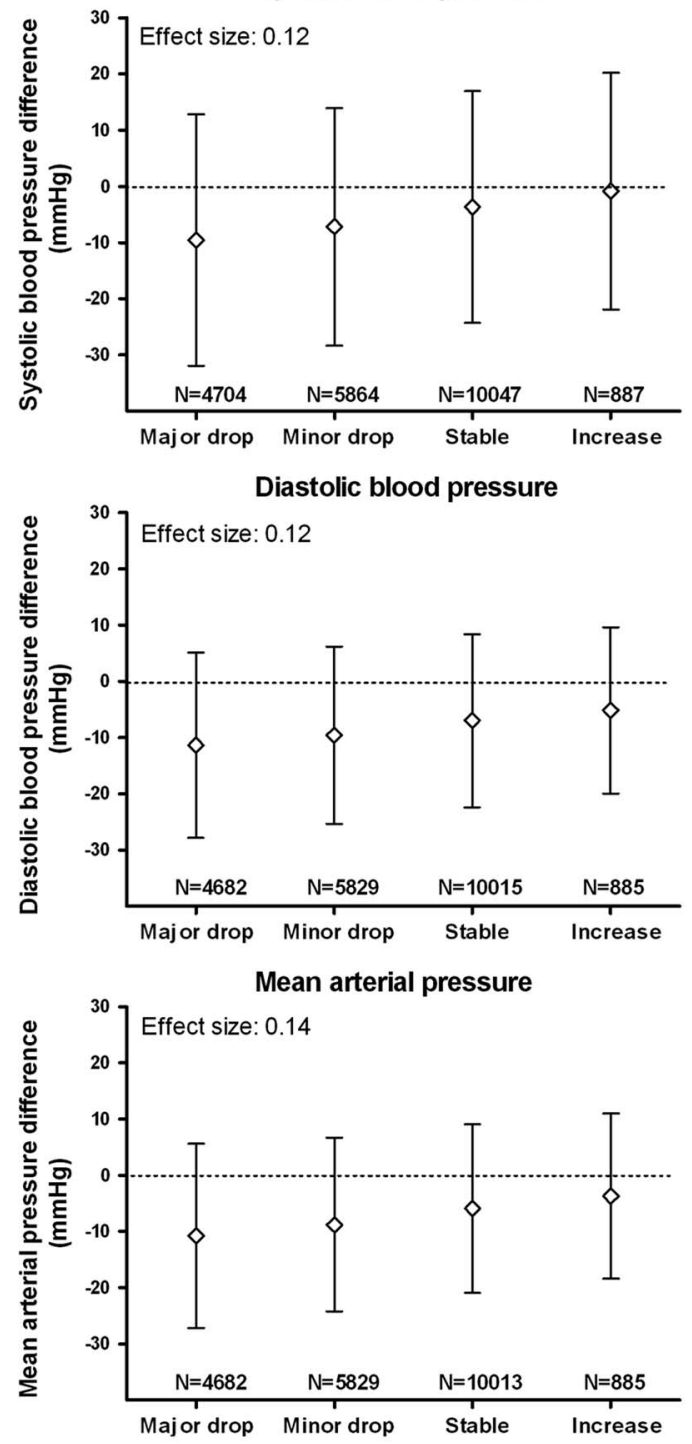

Heart rate

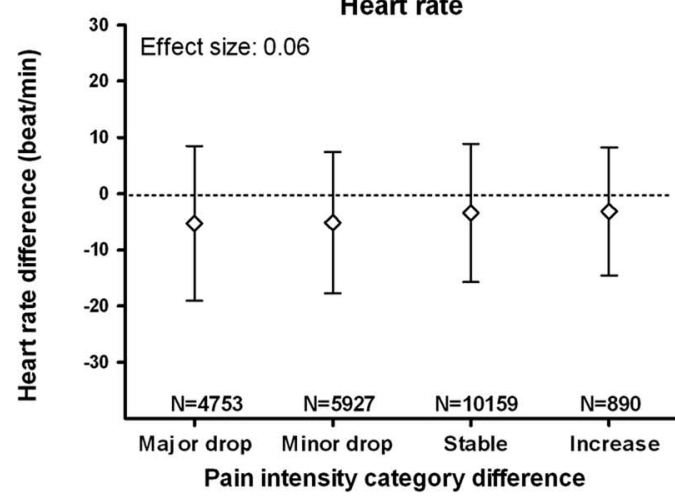

Painful conditions sample Systolic blood pressure
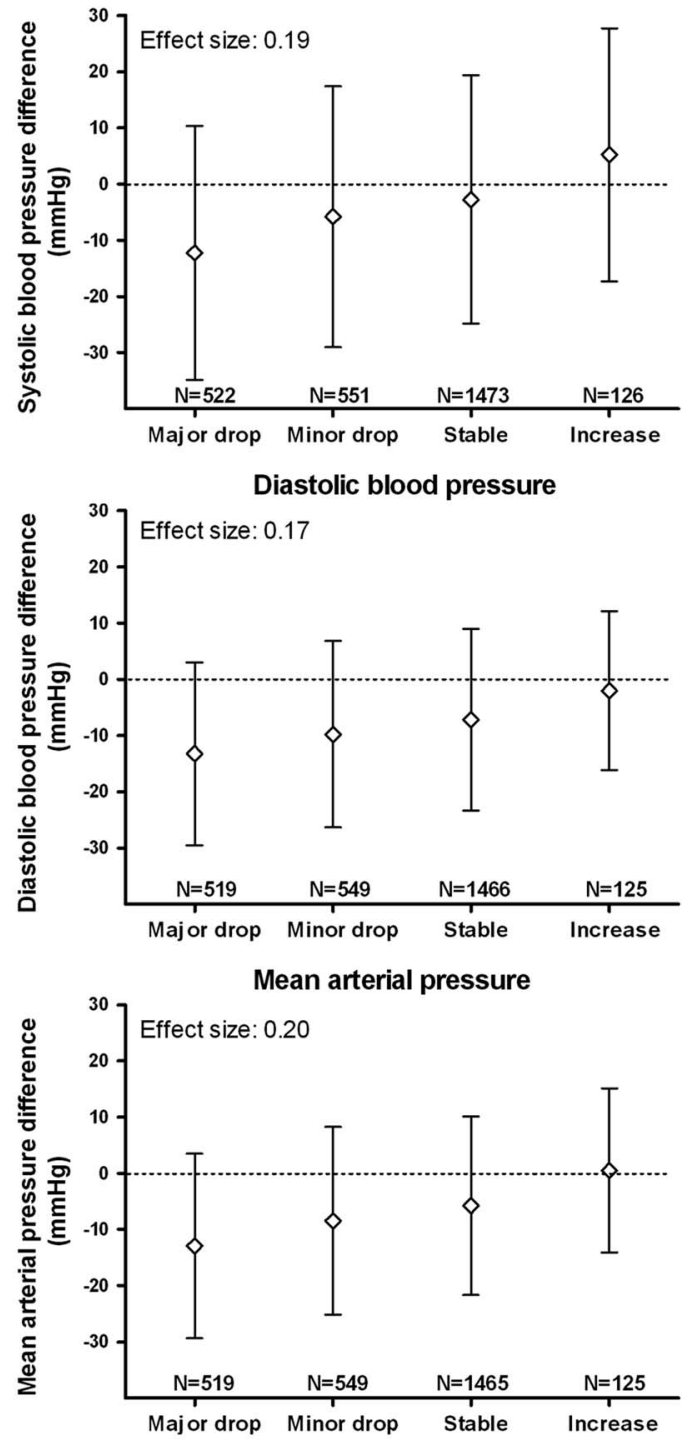

Heart rate

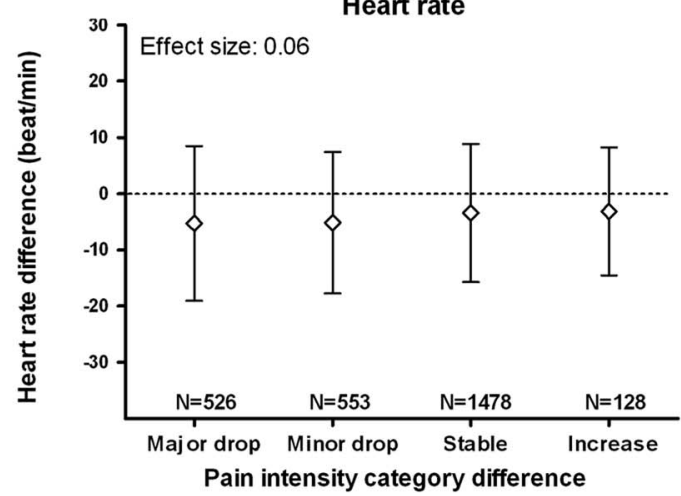

Figure 3. Mean $( \pm S D)$ changes in systolic, diastolic, mean arterial blood pressure and heart rate as a function of four levels of pain intensity change in the overall sample and in patients with recognized painful conditions. Cohen's one-way ANOVA effect sizes are also reported. 
A small sample can bias the finding toward a positive association if, by chance, patients with similar responses to pain are included in the study. Fazalbhoy et al, ${ }^{44}$ employing intramuscular infusion of hypertonic saline to evoke pain, determined that muscle sympathetic nerve activity, blood pressure, and HR were increased in some subjects, while others presented decreased variables. Furthermore, these responses were constant over time.

Many health care professionals still believe that vital signs are useful to validate pain intensity, particularly if their impression is different from the patient's selfevaluation. Our study sheds light on a possible explanation. For the whole population, blood pressure and pulse varied slightly with changes in pain intensity over time. ES for HR, SBP, DBP, and MAP in our sample were larger for changes of pain intensity over time than for a specific level (particularly in recognized painful conditions). Consequently, physicians notice an association between changes in vital signs and variations in pain intensity in ED patients as a group. However, standard deviations are large, which makes it difficult to predict pain intensity level or variations associated with these vital signs in a single individual.

Pain encountered in EDs is generated by a wide array of pathologies, and a significant proportion of them could influence vital signs independent of the pain they cause. In our study, age and gender were more associated with pain intensity than vital signs. When health care professionals notice sudden variation in vital signs, they should re-evaluate patients' medical conditions, including pain intensity. However, these changes in vital signs should not be attributed primarily to variations in pain intensity.

Our study has potential limitations. Data were not recorded specifically to address the study objectives. Database accuracy depends on personnel who enter the data. However, nurses are well aware of the importance of accurate and detailed charting. Moreover, triage nurses receive comprehensive training in administering the pain intensity scale, and the electronic interface prompts them to adopt specific wording as well as completion of an 11-point numerical scale to evaluate pain intensity.

The stimuli generating pain were not standardized; however, it appears that perceived pain is more closely related to vital signs than stimuli intensity. ${ }^{22,27,30,31}$ Furthermore, the retrospective study design could not control for vital signs prior to the pain stimuli and for other factors that could influence changes in vital signs.
On the other hand, the study has the following advantages: vital signs were measured automatically by electronic sphygmomanometer and the record review was performed by computer. Indeed, computerized medical record review has been shown to be more efficient and accurate than manual review of ED records. ${ }^{45}$

\section{CONCLUSION}

ED vital signs (heart rate, systolic, diastolic, and mean arterial blood pressures) should not be used to estimate or substantiate self-reported acute pain intensity levels. The study conclusions also apply for variations in pain intensity over time for an individual patient.

Competing Interests: The statistical analysis part of the study was supported by the Emergency Department Research Fund of Hôpital du Sacré-Coeur de Montréal.

\section{REFERENCES}

1. National Hospital Ambulatory Medical Care Survey. 2010 Emergency Department Summary Tables. National health statistics reports. Hyattsville, MD: National Center for Health Statistics; 2010.

2. Cordell WH, Keene KK, Giles BK, et al. The high prevalence of pain in emergency medical care. Am 7 Emerg Med 2002;20(3):165-9.

3. Todd KH, Ducharme J, Choiniere M, et al. Pain in the emergency department: results of the pain and emergency medicine initiative (PEMI) multicenter study. 7 Pain 2007; $8(6): 460-6$.

4. Selbst SM, Clark M. Analgesic use in the emergency department. Ann Emerg Med 1990;19(9):1010-3.

5. Todd KH, Sloan EP, Chen C, et al. Survey of pain etiology, management practices and patient satisfaction in two urban emergency departments. CFEM 2002;4(4):252-6.

6. Silka PA, Roth MM, Moreno G, et al. Pain scores improve analgesic administration patterns for trauma patients in the emergency department. Acad Emerg Med 2004;11(3):264-70.

7. Stalnikowicz R, Mahamid R, Kaspi S, et al. Undertreatment of acute pain in the emergency department: a challenge. Int 7 Qual Health Care 2005;17(2):173-6.

8. Grant PS. Analgesia delivery in the ED. Am 7 Emerg Med 2006;24(7):806-9.

9. Chen EH, Shofer FS, Dean AJ, et al. Gender disparity in analgesic treatment of emergency department patients with acute abdominal pain. Acad Emerg Med 2008;15(5):414-8.

10. Singer AJ, Garra G, Chohan JK, et al. Triage pain scores and the desire for and use of analgesics. Ann Emerg Med 2008;52(6):689-95.

11. Yanuka M, Soffer D, Halpern P. An interventional study to improve the quality of analgesia in the emergency department. CFEM 2008;10(5):435-9. 
12. Pines JM, Shofer FS, Isserman JA, et al. The effect of emergency department crowding on analgesia in patients with back pain in two hospitals. Acad Emerg Med 2010; 17(3):276-83.

13. Abbuhl FB, Reed DB. Time to analgesia for patients with painful extremity injuries transported to the emergency department by ambulance. Prehosp Emerg Care 2003;7(4): 445-7.

14. Shabbir J, Ridgway PF, Lynch K, et al. Administration of analgesia for acute abdominal pain sufferers in the accident and emergency setting. Eur 7 Emerg Med 2004;11(6):309-12.

15. Tanabe P, Myers R, Zosel A, et al. Emergency department management of acute pain episodes in sickle cell disease. Acad Emerg Med 2007;14(5):419-25.

16. Hwang U, Richardson LD, Sonuyi TO, et al. The effect of emergency department crowding on the management of pain in older adults with hip fracture. $7 \mathrm{Am}$ Geriatr Soc 2006;54(2):270-5.

17. Mitchell R, Kelly AM, Kerr D. Does emergency department workload adversely influence timely analgesia? Emerg Med Australas 2009;21(1):52-8.

18. Neighbor ML, Honner S, Kohn MA. Factors affecting emergency department opioid administration to severely injured patients. Acad Emerg Med 2004;11(12):1290-6.

19. Daoust R, Paquet J, Lavigne G, et al. Senior patients with moderate to severe pain wait longer for analgesic medication in EDs. Am 7 Emerg Med 2014;32(4):315-9.

20. Rundshagen I, Schnabel K, Standl T, et al. Patients' vs nurses' assessments of postoperative pain and anxiety during patient- or nurse-controlled analgesia. Bri 7 Anaesth 1999; 82(3):374-8.

21. Mantyselka P, Kumpusalo E, Ahonen R, et al. Patients' versus general practitioners' assessments of pain intensity in primary care patients with non-cancer pain. Br 7 Gen Pract 2001;51(473):995-7.

22. Moltner A, Holzl R, Strian F. Heart rate changes as an autonomic component of the pain response. Pain 1990; 43(1):81-9.

23. Hampf G. Influence of cold pain in the hand on skin impedance, heart rate and skin temperature. Physiol Bebav 1990;47(1):217-8.

24. Bendall JC, Simpson PM, Middleton PM. Prehospital vital signs can predict pain severity: analysis using ordinal logistic regression. Eur 7 Emerg Med 2011;18(6):334-9.

25. Bossart P, Fosnocht D, Swanson E. Changes in heart rate do not correlate with changes in pain intensity in emergency department patients. 7 Emerg Med 2007;32(1):19-22.

26. Landrum A, Watson L. Verbal pain scores and their association with vital signs in the post anesthesia care unit. 7 Pain 2011;12(4 Suppl 1):P7.

27. Loggia ML, Juneau M, Bushnell MC. Autonomic responses to heat pain: Heart rate, skin conductance, and their relation to verbal ratings and stimulus intensity. Pain 2011;152(3): 592-8.

28. Marco CA, Plewa MC, Buderer N, et al. Self-reported pain scores in the emergency department: lack of association with vital signs. Acad Emerg Med 2006;13(9):974-9.
29. Tousignant-Laflamme Y, Marchand S. Sex differences in cardiac and autonomic response to clinical and experimental pain in LBP patients. Eur 7 Pain 2006;10(7):603-14.

30. Tousignant-Laflamme Y, Rainville P, Marchand S. Establishing a link between heart rate and pain in healthy subjects: a gender effect. 7 Pain 2005;6(6):341-7.

31. Arbour C, Gelinas C. Are vital signs valid indicators for the assessment of pain in postoperative cardiac surgery ICU adults? Intensive Crit Care Nurs 2009;26(2):83-90.

32. Chang LH, Ma TC, Tsay SL, et al. Relationships between pain intensity and heart rate variability in patients after abdominal surgery: a pilot study. Chin Med $\mathcal{F}$ 2012;125(11):1964-9.

33. Ledowski T, Reimer M, Chavez V, et al. Effects of acute postoperative pain on catecholamine plasma levels, hemodynamic parameters, and cardiac autonomic control. Pain 2012;153(4):759-64.

34. Treister R, Kliger M, Zuckerman G, et al. Differentiating between heat pain intensities: the combined effect of multiple autonomic parameters. Pain 2012;153(9):1807-14.

35. Peckerman A, Saab PG, McCabe PM, et al. Blood pressure reactivity and perception of pain during the forehead cold pressor test. Psychophysiology 1991;28(5):485-95.

36. Bartfield JM, Janikas JS, Lee RS. Heart rate response to intravenous catheter placement. Acad Emerg Med 2003; 10(9):1005-8.

37. Fowler M, Slater TM, Garza TH, et al. Relationships between early acute pain scores, autonomic nervous system function, and injury severity in wounded soldiers. 7 Trauma 2011;71(1 Suppl):S87-90.

38. Ledowski T, Tiong WS, Lee C, et al. Analgesia nociception index: evaluation as a new parameter for acute postoperative pain. Bri 7 Anaesth 2013;111(4):627-9.

39. Lord B, Woollard M. The reliability of vital signs in estimating pain severity among adult patients treated by paramedics. Emerg Med 7 2011;28(2):147-50.

40. Boselli E, Daniela-Ionescu M, Begou G, et al. Prospective observational study of the non-invasive assessment of immediate postoperative pain using the analgesia/nociception index (ANI). Bri 7 Anaesth 2013;111(3):453-9.

41. Ledowski T, Albus S, Stein J, et al. Skin conductance for monitoring of acute pain in adult postoperative patients: influence of electrode surface area and sampling time. 7 Clin Monit Comput 2011;25(6):371-6.

42. Ledowski T, Stein J, Albus S, et al. The influence of age and sex on the relationship between heart rate variability, haemodynamic variables and subjective measures of acute postoperative pain. Eur 7 Anaesthesiol 2011;28(6):433-7.

43. Coniam S, Mendham J. Principles of Pain Management for Anaesthetists. Boca Raton, FL: CRC Press; 2005.

44. Fazalbhoy A, Birznieks I, Macefield VG. Consistent interindividual increases or decreases in muscle sympathetic nerve activity during experimental muscle pain. Exp Brain Res 2014;232(4):1309-15.

45. Biese KJ, Forbach CR, Medlin RP, et al. Computer-facilitated review of electronic medical records reliably identifies emergency department interventions in older adults. Acad Emerg Med 2013;20(6):621-8. 